\title{
Cationic Oligomerization of Ethylene Oxide
}

\author{
Shiro KobaYASHI, Takatoshi KobaYASHI, and Takeo SAEgUSA \\ Department of Synthetic Chemistry, Faculty of Engineering, \\ Kyoto University, Kyoto 606, Japan
}

(Received July 29, 1983)

\begin{abstract}
The oligomerization of ethylene oxide (EO) was investigated with several cationic catalysts to find a method for producing cyclic oligomers (crown ethers). The reactions were monitored by NMR spectroscopy $\left({ }^{1} \mathrm{H}\right.$ and $\left.{ }^{19} \mathrm{~F}\right)$ and gas chromatography. The composition of oligomers was found to change during the reactions, and the production of 1,4-dioxane increased at the later stage of the reactions. This indicates that the composition of oligomers is kinetically controlled. The formation of higher cyclic oligomers was favored by the addition of tetrahydropyran or 1,4-dioxane to the system catalyzed by an oxonium salt; the maximum yield of cyclic tetramer was $16.8 \%$. The effect of alkali metal salts was also examined. A template effect was observed to increase the amount of cyclic oligomer production.

KEY WORDS Cationic Oligomerization / Ethylene Oxide / Cyclic Oligomers / Crown Ether / Kinetically Controlled Reaction / Additive Effects of Metal Salts / Template Effect /
\end{abstract}

An extensive study was recently carried out on the cationic polymerization of heterocyclic monomers which, it was found, may lead to polymers containing significant amounts of linear and cyclic oligomers. ${ }^{1}$ The most thoroughly studied monomer was ethylene oxide (EO). Eastham et al. observed that the cationic polymerization of $\mathrm{EO}$ resulted in the production of a mixture of poly(EO) and 1,4dioxane (DON). ${ }^{2}$ Recently we reported that EO was converted to 1,4-dioxane selectively and quantitatively when EO was treated with superacid esters such as ethyl trifluoromethanesulfonate $\left(\mathrm{EtOSO}_{2} \mathrm{CF}_{3}\right)$ and fluorosulfonate $\left(\mathrm{EtOSO}_{2} \mathrm{~F}\right){ }^{3} \mathrm{On}$ the other hand, Dale et al. found that EO leads to a mixture of cyclic oligomers and polymers when treated with fluorine-containing metal catalysts such as antimony pentafluoride or $1: 1$ mixture of boron trifluoride and hydrogen fluoride. ${ }^{4}$ The amount of cyclic oligomers produced changed with a catalyst employed. In the present study, we examine EO oligomerization with several catalysts, monitoring the change in products as a function of reaction time. The possibility of the selective production of higher cyclic oligomers, a family of crown ethers, was examined.

\section{EXPERIMENTAL}

\section{Materials}

All reagents were distilled under nitrogen. A commercial sample of EO was distilled twice. Tetrahydropyran (THP) and DON were dried with sodium metal and distilled. This procedure was also repeated twice. Purification of solvents and $m$ xylene, nitrobenzene as the glpc internal standard was carried out in the same way as in the previous work. ${ }^{5}$ Triethyloxonium tetrafluoroborate $\left(\mathrm{Et}_{3} \mathrm{O}^{+} \cdot \mathrm{BF}_{4}^{-}\right)$was synthesized and purified by Meewein's method. ${ }^{6}$ Ethyl trifluoromethanesulfonate $\left(\mathrm{EtOSO}_{2} \mathrm{CF}_{3}\right)$ was prepared in the same manner as reported. ${ }^{7}$ Commercial stannic chloride $\left(\mathrm{SnCl}_{4}\right)$ and boron trifluoride etherate $\left(\mathrm{Et}_{2} \mathrm{O} \cdot \mathrm{BF}_{3}\right)$ were purified by fractional distillation before use. Boron trifluoride $\left(\mathrm{BF}_{3}\right)$ was prepared from $\mathrm{NaBF}_{4}-$ $\mathrm{B}_{2} \mathrm{O}_{3}$ and conc. $\mathrm{H}_{2} \mathrm{SO}_{4}{ }^{8}$ it, as well as hydrogen fluoride (HF) were used as benzene solutions. The catalyst concentrations were determined by gravimetric analysis and fluoride ion concentration measurement. Poly(EO) was purified by reprecipitation. ${ }^{2 b}$ Alkali metal fluoroborates were synthesized and purified by Shapiro's procedure, ${ }^{9}$ and alkali metal triflates were similarly synthesized 
from alkali metal carbonates and trifluoromethanesulfonic acid $\left(\mathrm{CF}_{3} \mathrm{SO}_{3} \mathrm{H}\right)$.

\section{Oligomerization Procedure and Analysis of Products}

A typical run was as follows: into a $30 \mathrm{ml}$ test tube provided with a three way stopcock, EO was introduced at $-78^{\circ} \mathrm{C}$ under nitrogen. To the tube, a solvent, an internal standard material ( $m$-xylene or nitrobenzene), and a catalyst were added with a small syringe. During the sample preparation, the tube was cooled in a dry ice-ethanol bath. The tube was sealed with the cock and the mixture was stirred magnetically with a spin bar at a constant temperature. A portion of the mixture was taken into an NMR sample tube which was then sealed off and maintained at the reaction temperature with occasional shaking; its ${ }^{1} \mathrm{H}$ NMR spectra were recorded so as to follow the consumption of EO. The production of oligomers was followed by glpc analysis; i.e., a sample was taken with a small syringe through the cock at appropriate intervals of time, quenched by sodium methoxide-methanol solution at $-78^{\circ} \mathrm{C}$, and subjected to glpc analysis. Identification and quantification of the quenched products were performed by a comparison of the retention time with that of the authentic samples and by the peak intensity, respectively. Furthermore, the quenched oligomers were isolated by preparative glpc and identified by NMR and mass spectroscopy and elemental analysis. The products quenched with $\mathrm{CH}_{3} \mathrm{ONa}$ are given by eq 1 .

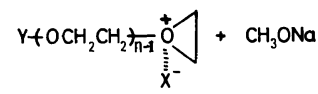

$$
\begin{aligned}
& \left.\longrightarrow \mathrm{Y}+\mathrm{OCH}_{2} \mathrm{CH}_{2}\right)_{\mathrm{n}}-\mathrm{OCH}_{3}+\mathrm{NaX}
\end{aligned}
$$

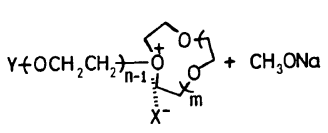

$$
\begin{aligned}
& \left.\longrightarrow \mathrm{Y}+\mathrm{OCH}_{2} \mathrm{CH}_{2}+\mathrm{n}_{\mathrm{n}-1} \mathrm{OCH}_{3}+\underset{\mathrm{O}_{\mathrm{m}}^{\mathrm{O}}}{\mathrm{O} x}+\mathrm{NaX}\right]
\end{aligned}
$$

In the polymerization with an alkali metal salt, after quenching the reaction mixture with sodium methoxide, the solution was neutralized with dilute $\mathrm{HCl}$ and extracted twice with $\mathrm{CH}_{2} \mathrm{Cl}_{2}$ to obtain the products.

\section{NMR Measurement and Molecular Weight Deter- mination}

The reaction was followed by ${ }^{19} \mathrm{~F}$ or ${ }^{1} \mathrm{H}$ NMR spectroscopy as previously reported, ${ }^{3,7,10}$ using a Hitachi R-20B NMR spectrometer equipped with radiofrequency units for protons $(60 \mathrm{MHz})$ and fluorine-19 (56.456 MHz) and a Varian HA- $100{ }^{1} \mathrm{H}$ NMR spectrometer. The molecular weight of the poly(EO) was measured by vapor pressure osmometry in $\mathrm{CHCl}_{3}$ at $35^{\circ} \mathrm{C}$.

\section{RESULTS AND DISCUSSION}

\section{Oligomer Distribution with Several Cationic Cata- lysts \\ 1) Triethyloxonium Tetrafluoroborate $\left(\mathrm{Et}_{3} \mathrm{O}^{+}\right.$.} $\mathrm{BF}_{4}^{-}$) Catalyst. The time-production curves of oligomers in $\mathrm{EO}$ oligomerization with $\mathrm{Et}_{3} \mathrm{O}^{+}$. $\mathrm{BF}_{4}^{-}$in $\mathrm{CH}_{2} \mathrm{Cl}_{2}$ at $25^{\circ} \mathrm{C}$ are shown in Figure 1. The product was a mixture of linear and cyclic oligomers. The linear oligomers had the form $\mathrm{Et}\left(-\mathrm{OCH}_{2} \mathrm{CH}_{2}\right)_{n} \mathrm{OCH}_{3}(n=1-4)$ and the cyclic oligomers were DON and cyclic tetramer. Higher linear oligomers and cyclic trimer could not be found under our conditions for analysis, although trace amounts may have been formed. The amount of cyclic tetramer first increased with reaction time, reached a maximum, and then decreased. The amounts of linear oligomers slowly increased with reaction time and then gradually decreased after reaching a maximum. The cyclic dimer, DON, which was the most thermodynamically stable product, continued to increase with reaction time throughout the reaction. After the EO monomer had been completely consumed, linear oligomers $(n=3,4)$ and a cyclic tetramer were converted into DON. Thus the yield of DON became almost quantitative (about $94 \%$ ).

The above transformation was confirmed using triethyleneglycol dimethyl ether $(n=3)$ and 15crown- 5 as model compounds. When these model compounds were treated with $\mathrm{Et}_{3} \mathrm{O}^{+} \cdot \mathrm{BF}_{4}^{-}$under the same reaction conditions, the formation of a cyclic tetramer, DON, and linear oligomers $(n=1-$ 4) were observed half way through the reaction. However, these products were finally converted into DON. The formation of intermediate products from a higher oligomer $(n=4)$ can be explained by the oxonium scrambling reaction in EO oligomerization with $\mathrm{Et}_{3} \mathrm{O}^{+} \cdot \mathrm{BF}_{4}{ }^{-}$catalyst. 


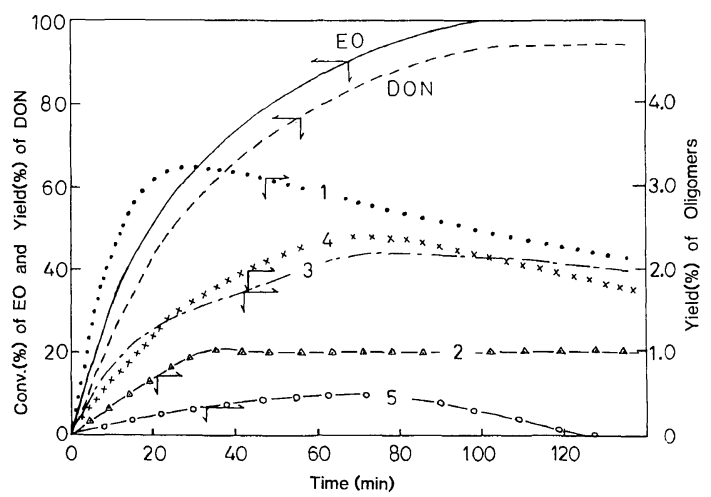

Figure 1. Time-conversion curves in the cationic oligomerization of EO $\left(2.10 \mathrm{~mol}^{-1}\right)$ with the $\mathrm{Et}_{3} \mathrm{O}^{+} \cdot \mathrm{BF}_{4}{ }^{-}$catalyst $\left(4.6 \mathrm{~mol} \%\right.$ for $\mathrm{EO}$ ) in $\mathrm{CH}_{2} \mathrm{Cl}_{2}$ at $25^{\circ} \mathrm{C}$ : curve 1 (cyclic tetramer); curve 2 (ethylene glycol ethyl methyl ether); curve 3 (linear dimer); curve 4 (linear trimer); curve 5 (linear tetramer).

The formation of linear oligomers, the cyclic tetramer and DON from cyclic pentamer indicates the degradation of intermediate oxonium ions, as shown in eq 2.

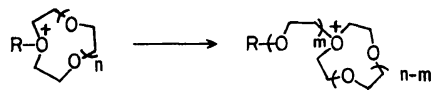

In $\mathrm{EO}$ oligomerization with $\mathrm{Et}_{3} \mathrm{O}^{+} \cdot \mathrm{BF}_{4}{ }^{-}$, the cyclic trimer was not detected, due to the unfavorable nine-membered ring of the cyclic trimer.

These findings show that EO oligomerization with $\mathrm{Et}_{3} \mathrm{O}^{+} \cdot \mathrm{BF}_{4}{ }^{-}$is a kinetically controlled process; i.e., the composition of oligomers changes with reaction time and eventually oligomers are converted to the thermodynamically very stable product, DON.

Variation in reaction conditions causes the composition of products to change (Table I, No. 1-4). Here, the maximum yield of each oligomer from the EO monomer during the course of oligomerization is given. When the initial EO concentration was lowered, the amounts of cyclic oligomers increased and those of the linear oligomers were reduced. The increase in the cyclic tetramer was pronounced when benzene was used as the solvent. This system was at first heterogeneous, and then homogeneous as the oligomerization proceeded.

The production of DON was affected by reaction temperature. Table II shows that DON formation decreased with increasing reaction temperature. At 25 and $0^{\circ} \mathrm{C}$, DON formation was almost quantitative. At $35^{\circ} \mathrm{C}$, a higher oligomeric product was produced. The reaction mixture (with
$\mathrm{Et}_{3} \mathrm{O}^{+} \cdot \mathrm{BF}_{4}^{-}$in $\mathrm{CH}_{2} \mathrm{Cl}_{2}$ ) was quenched by $\mathrm{NH}_{4} \mathrm{OH}$-methanol solution, and the quenched solution was poured into $n$-hexane. The oligomer, insoluble in $n$-hexane, was isolated and dried in vacuo at $60^{\circ} \mathrm{C}$. The molecular weight was determined by vapor pressure osmometry to be 450 .

In the $100 \mathrm{MHz}{ }^{1} \mathrm{H}$ NMR spectrum of the oligomer in $\mathrm{CDCl}_{3}$, besides the signal at $3.6 \mathrm{ppm}$ ascribed to methylene protons of $-\mathrm{OCH}_{2}$ and the very small one at $1.20 \mathrm{ppm}$ ascribed to methyl protons of terminals, a quartet at $4.78 \mathrm{ppm}$ and a doublet $1.33 \mathrm{ppm}$ could be seen. These were assigned to a methine proton $\left(\mathrm{OC} \mathrm{H}-\mathrm{CH}_{3}\right)$ and to methyl protons $\left(\mathrm{OCH}-\mathrm{CH}_{3}\right)$ of an acetal type of acetaldehyde, respectively. ${ }^{11}$ Thus, the polymer structure consisted of $\left(\mathrm{OCH}_{2} \mathrm{CH}_{2}\right)$ and $\left(\mathrm{OCH}\left(\mathrm{CH}_{3}\right) \mathrm{O}\right)$ as the major and minor units, respectively. The latter was probably formed by the isomerization of the oxonium ions (1) into an oxo-carbenium ions (2).

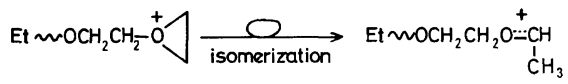

$$
\begin{aligned}
& 12
\end{aligned}
$$

In the oligomerization at $0^{\circ} \mathrm{C}$ or $25^{\circ} \mathrm{C}$, no acetal units could be detected by ${ }^{1} \mathrm{H}$ NMR in the oligomers.

2) Ethyl Trifluoromethanesulfonate. It has been reported that EO is converted quantitatively to DON when treated with a catalytic amount of a superacid derivative such as ethyl trifluoromethanesulfonate (EtOTf) and the mechanism has been investigated. ${ }^{3}$ In the present study, EO oligomer- 
Table I. Cationic oligomerization of EO with various catalysts

\begin{tabular}{|c|c|c|c|c|c|c|c|c|c|}
\hline \multirow{3}{*}{ No. } & \multirow{3}{*}{$\frac{[\mathrm{EO}]_{0}}{\mathrm{moll}^{-1}}$} & \multirow{3}{*}{ Catalyst } & \multirow{3}{*}{$\frac{[\mathrm{I}]_{0}^{\mathrm{a}}}{\mathrm{moll}^{-1}}$} & \multirow{3}{*}{ Solvent } & \multirow{3}{*}{$\frac{\text { Temp }}{{ }^{\circ} \mathrm{C}}$} & \multicolumn{4}{|c|}{ Products $/ \%$ b } \\
\hline & & & & & & \multicolumn{2}{|c|}{ Linear oligomers } & \multicolumn{2}{|c|}{ Cyclic oligomers } \\
\hline & & & & & & $n=3$ & $n=4$ & DON & Tetramer \\
\hline 1 & 2.10 & $\mathrm{Et}_{3} \mathrm{O}^{+} \cdot \mathrm{BF}_{4}^{-}$ & 4.6 & $\mathrm{CH}_{2} \mathrm{Cl}_{2}$ & 25 & 2.4 & 0.5 & 94 & 3.2 \\
\hline 2 & 0.75 & $\mathrm{Et}_{3} \mathrm{O}^{+} \cdot \mathrm{BF}_{4}^{-}$ & 5.8 & $\mathrm{CH}_{2} \mathrm{Cl}_{2}$ & 25 & 7.2 & 0.8 & 95 & 4.2 \\
\hline 3 & 5.20 & $\mathrm{Et}_{3} \mathrm{O}^{+} \cdot \mathrm{BF}_{4}^{-}$ & 4.6 & $\mathrm{CH}_{2} \mathrm{Cl}_{2}$ & 0 & 3.2 & 0.7 & 96 & 2.3 \\
\hline 4 & 0.96 & $\mathrm{Et}_{3} \mathrm{O}^{+} \cdot \mathrm{BF}_{4}^{-}$ & 5.8 & $\mathrm{C}_{6} \mathrm{H}_{6}$ & 25 & 3.6 & 0 & 86 & 14.5 \\
\hline 5 & 1.80 & EtOTf & 36 & $\mathrm{CH}_{2} \mathrm{Cl}_{2}$ & 25 & 6.6 & 0 & 85 & 0 \\
\hline 6 & 1.20 & EtOTf & 40 & DON & 35 & 5.7 & 0.8 & - & 2.8 \\
\hline 7 & 1.62 & EtOTf & 40 & $\mathrm{CH}_{3} \mathrm{NO}_{2}$ & 35 & 4.8 & 0.6 & 91 & 3.8 \\
\hline 8 & 0.96 & $\mathrm{Et}_{2} \mathrm{OBF}_{3}$ & 4.5 & $\mathrm{CH}_{2} \mathrm{Cl}_{2}$ & 25 & 5.0 & 4.2 & 88 & 8.0 \\
\hline 9 & 0.91 & $\mathrm{BF}_{3}$ & 0.8 & $\mathrm{C}_{6} \mathrm{H}_{6}$ & 20 & 10.3 & - & 62 & 8.0 \\
\hline 10 & 2.30 & $\mathrm{BF}_{3}-\mathrm{HF}(1: 1)^{\mathrm{c}}$ & 0.8 & DON & 20 & 8.1 & - & - & 3.8 \\
\hline 11 & 2.15 & $\mathrm{BF}_{3}-\mathrm{HF}(1: 1)^{\mathrm{c}}$ & 0.8 & $\mathrm{C}_{6} \mathrm{H}_{6}$ & 20 & 9.2 & - & 58 & 3.2 \\
\hline 12 & 1.54 & $\mathrm{SnCl}_{4}$ & 2.5 & $\mathrm{CH}_{2} \mathrm{Cl}_{2}$ & 25 & 0 & 0 & 28 & 0 \\
\hline
\end{tabular}

a $[\mathrm{I}]_{0}=\mathrm{mol} \%$ for the initial EO concentration.

b The maximum values based on EO during the reaction.

c $\mathrm{BF}_{3}-\mathrm{HF}$ catalyst system; mole ratio $=1: 1$.

Table II. Effects of reaction temperature on DON yield during $\mathrm{EO}$ oligomerization with $\mathrm{Et}_{3} \mathrm{O}^{+} \cdot \mathrm{BF}_{4}^{-}$in $\mathrm{CH}_{2} \mathrm{Cl}_{2}$ when the amount of DON ceased to change ${ }^{\mathrm{a}}$

\begin{tabular}{|c|c|}
\hline Reaction temp & DON yield \\
\hline${ }^{\circ} \mathrm{C}$ & $\%$ \\
\hline 0 & 98 \\
\hline 25 & 96 \\
\hline 35 & 79 \\
\hline 45 & 75 \\
\hline 60 & 55 \\
\hline
\end{tabular}

a Initial conditions: $[\mathrm{EO}]_{0}=5.2 \mathrm{~mol} 1^{-1}, \quad[\mathrm{I}]_{0}=0.2$ moll ${ }^{-1}$.

ization with an EtOTf catalyst was examined for a comparison with an $\mathrm{Et}_{3} \mathrm{O}^{+} \cdot \mathrm{BF}_{4}^{-}$catalyst. Oligomer formations with EtOTf in $\mathrm{CH}_{2} \mathrm{Cl}_{2}$ at $25^{\circ} \mathrm{C}$ are shown in Table I. The produced oligomers in this case were only DON as a cyclic and linear oligomers $(n=1-3)$. Other higher oligomers, i.e., the cyclic and linear tetramers, could not be found. Variation in the amounts of oligomers versus reaction time was similar to that when using the $\mathrm{Et}_{3} \mathrm{O}^{+} \cdot \mathrm{BF}_{4}{ }^{-}$catalyst. The linear trimer completely disappeared $1 \mathrm{~h}$ after the beginning of the reaction and the amount of DON increased with reaction time and became almost quantitative. These results are in accord with those of previous work. ${ }^{3}$ In the EtOTf catalyst system, the ester (3)-oxonium ion (4) equilibrium of the propagating species (eq 4) was established. ${ }^{3,5}$ Due to the reduced reactivity of propagation by EtOTf, the back-biting reaction was

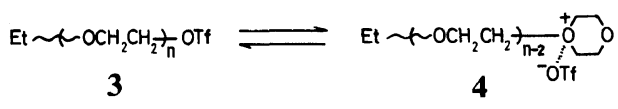

primarily yielding DON selectively. The $\mathbf{3} \rightleftarrows 4$ equilibrium was very much dependent on the reaction solvent employed. When the solvent was changed from $\mathrm{CH}_{2} \mathrm{Cl}_{2}$ to DON and $\mathrm{CH}_{3} \mathrm{NO}_{2}$, the cyclic and linear tetramers were produced, but no other higher oligomers were detected (Table I). By ${ }^{19} \mathrm{~F}$ NMR spectroscopy, oxonium ions (demonstrated by fluoride anion) were actually found by about 10 percent in $\mathrm{CH}_{3} \mathrm{NO}_{2}$ and 3 percent in DON. ${ }^{3}$ Due to the larger contribution of the oxonium ions in these solvents, the propagation leading to longer linear oligomers became more rapid, ${ }^{3}$ and thus the back-biting reaction was able to produce the cyclic tetramer in addition to DON.

3) Other catalysts. Other fluorine containing catalysts were examined such as boron trifluoride $\left(\mathrm{BF}_{3}\right)$, boron trifluoride etherate, $\left(\mathrm{BF}_{3} \mathrm{OEt}_{2}\right)$, and boron trifluoride $\left(\mathrm{BF}_{3}\right)$-hydrogen fluoride $(\mathrm{HF})$ 
Table III. Cationic oligomerization of $\mathrm{EO}$ with $\mathrm{Et}_{3} \mathrm{O}^{+} \cdot \mathrm{BF}_{4}{ }^{-}$in the presence of THP or DON at $25^{\circ} \mathrm{C}$

\begin{tabular}{|c|c|c|c|c|c|c|}
\hline \multicolumn{3}{|c|}{ Initial condition } & \multicolumn{4}{|c|}{ Product $/ \%^{a}$} \\
\hline \multirow{2}{*}{$\frac{[\mathrm{EO}]_{0}}{\operatorname{mol~1}{ }^{-1}}$} & \multirow{2}{*}{$\frac{[\mathrm{I}]_{0}}{\mathrm{~mol} \% \text { for } \mathrm{EO}}$} & \multirow{2}{*}{ Solvent } & \multicolumn{2}{|c|}{ Linear oligomers } & \multicolumn{2}{|c|}{ Cyclic oligomers } \\
\hline & & & $n=3$ & $n=4$ & DON & Tetramer \\
\hline $0.75^{\mathrm{b}}$ & 5.8 & $\mathrm{CH}_{2} \mathrm{Cl}_{2}$ & 7.2 & 0.8 & 95 & 4.2 \\
\hline $0.75^{\mathrm{c}}$ & 4.6 & $\mathrm{CH}_{2} \mathrm{Cl}_{2}$ & 2.3 & -0 & 91 & 5.2 \\
\hline $0.94^{\mathrm{d}}$ & 4.6 & $\mathrm{CH}_{2} \mathrm{Cl}_{2}$ & 4.3 & 0.3 & 96 & 5.6 \\
\hline $0.75^{\mathrm{c}}$ & 5.8 & $\mathrm{C}_{6} \mathrm{H}_{6}$ & 4.9 & 1.3 & 93 & 16.8 \\
\hline
\end{tabular}

Table IV. Cationic oligomerization of EO with EtOTf in the presence of alkali metal triflates in $\mathrm{CH}_{2} \mathrm{Cl}_{2}$ at $35^{\circ} \mathrm{C}$ over a period of two weeks

\begin{tabular}{|c|c|c|c|c|c|c|}
\hline \multirow{3}{*}{$\begin{array}{c}\text { Salts } \\
\text { added }\end{array}$} & \multicolumn{6}{|c|}{ Product yield $/ \%$} \\
\hline & \multicolumn{2}{|c|}{ Linear oligomers } & \multicolumn{4}{|c|}{ Cyclic oligomers } \\
\hline & $n=3$ & $n=4$ & DON & Tetramer & Pentamer & Hexamer \\
\hline None & 0 & 0 & 91 & 0 & 0 & 0 \\
\hline LiOTf & 4.7 & 9.0 & 53 & 10.6 & 3.2 & Trace \\
\hline NaOTf & 2.8 & 4.3 & 68 & 3.0 & 4.6 & 3.2 \\
\hline KOTf & 5.3 & 6.5 & 56 & 2.5 & 3.8 & 4.2 \\
\hline
\end{tabular}

${ }^{\mathrm{a}}$ Initial conditions: $[\mathrm{EO}]_{0}=1.62 \mathrm{~mol} \mathrm{l}^{-1} ;[\mathrm{I}]_{0}=40 \mathrm{~mol} \%$; $[\mathrm{salt}] /[\mathrm{EO}]_{0}=0.4-0.6$.

(Table I). Variation in the amounts of oligomers as a function of reaction time was also similar to that of the above systems; i.e., product composition changed with time. Recently, it has been reported by Dale $e t$ al. that EO leads to a mixture of cyclic oligomers of $n=3,4, \cdots 9$, when treated with fluorine-containing catalysts such as a $1: 1$ mixture of $\mathrm{BF}_{3}$ and $\mathrm{HF}$ or antimony pentafluoride. ${ }^{4}$ But they did not describe the yield of oligomers from EO. One of the purposes of the present research was to determine this. Using $\mathrm{BF}_{3}$ or $\mathrm{BF}_{3}-\mathrm{HF}(1: 1$ molar ratio) in benzene at $20^{\circ} \mathrm{C}$, the maximum yield was about 8 percents. Linear oligomers and DON were also obtained. With the $\mathrm{BF}_{3}-\mathrm{HF}$ catalyst, the cyclic tetramer was obtained in a lesser amount, i.e., 3.8 and 3.2 percent (No. 10 and 11 in Table I). DON was the main product in all cases.

With $\mathrm{SnCl}_{4}$, on the other hand, EO led to the formation of waxy polymers instead of the lower oligomers reported by Eastham et al. ${ }^{2 \mathrm{c}}$ DON was produced in a relatively small amount $(28 \%)$. No other oligomers were produced.

\section{Effects of the Addition of Cyclic Ether}

In $\mathrm{EO}$ oligomerization with $\mathrm{Et}_{3} \mathrm{O}^{+} \cdot \mathrm{BF}_{4}{ }^{-}$, the yield of the cyclic tetramer increased by the addition of tretrahydropyran (THP) or DON (Table III). The reaction products themselves and the tendency for the amounts of the oligomers to change as a function of reaction time were basically the same without the additive.

The addition of THP or DON slightly increased the formation of the cyclic tetramer compared with systems without these compounds. The reaction of the EO oxonium species 5 and THP led to the formation of the THP oxonium species 6 . A pos- 
Table V. Cationic degradation of poly(EO) with $\mathrm{Et}_{3} \mathrm{O}^{+} \cdot \mathrm{BF}_{4}{ }^{-}$or EtOTf in the presence of lithium salts in $\mathrm{CH}_{2} \mathrm{Cl}_{2}$ at $35^{\circ} \mathrm{C}^{\mathrm{a}}$

\begin{tabular}{|c|c|c|c|c|c|c|}
\hline \multirow{2}{*}{$\begin{array}{l}\text { Starting } \\
\text { materials } \\
{[\mathrm{M}]}\end{array}$} & \multirow{2}{*}{ Salt } & \multirow{2}{*}{ Catalyst } & \multicolumn{4}{|c|}{ Cyclic oligomers $/ \%$ b } \\
\hline & & & DON & Tetramer & Pentamer & Hexamer \\
\hline \multirow{2}{*}{$\operatorname{Poly}(\mathrm{EO})^{\mathrm{c}}$} & $\mathrm{LiBF}_{4}$ & $\mathrm{Et}_{3} \mathrm{O}^{+} \cdot \mathrm{BF}_{4}^{-}$ & 76 & 3.8 & 2.3 & Trace \\
\hline & LiOTf & EtOTf & 91 & 4.3 & Trace & Trace \\
\hline \multirow{2}{*}{ TGDE $^{d}$} & $\mathrm{LiBF}_{4}$ & $\mathrm{Et}_{3} \mathrm{O}^{+} \cdot \mathrm{BF}_{4}^{-}$ & 88 & 2.4 & Trace & Trace \\
\hline & LiOTf & EtOTf & 96 & 2.8 & Trace & Trace \\
\hline \multicolumn{7}{|c|}{ 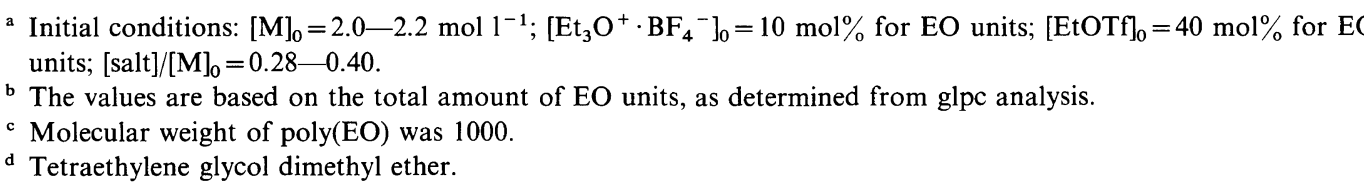 } \\
\hline
\end{tabular}

sible explanation for the effects of the additive is the more readily back-biting reaction of 6 to give cyclic oligomers than that of $\mathbf{5}$ since THP is very probably a leaving group in the back-biting reaction.

$$
m \mathrm{OCH}_{2} \mathrm{CH}_{2} \frac{+}{n}+\sqrt{O}
$$

5

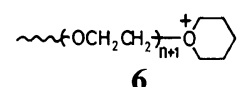

\section{Effects of the Addition of Alkali Metal Salts}

It has been reported that macrocyclic polyethers, the so-called "crown ethers" form stable complexes with the alkali and alkali earth metal cations. On this basis, Greene ${ }^{12}$ carried out the synthesis of 18crown-6. In the polymerization of EO, Dale et al. performed the direct synthesis of the crown ethers from EO through the template effects of alkali metal cations. ${ }^{4 \mathrm{~d}}$ But the yields of the crown ethers were not reported and only the composition of a mixture of cyclic oligomers was described. Therefore, we examined this point. Alkali metal trifluoromethanesulfonates (alkali metal triflate) were used for the template in the EtOTf catalyzed oligomerization of EO. EO was added slowly to a cooled suspension of an insoluble salt in $\mathrm{CH}_{2} \mathrm{Cl}_{2}$ containing the catalyst. The salt partially dissolved in this solution. As the reaction proceded, the reaction turned gelatinous. When adding an alkali triflate, the consumption of EO became much slower, probably due to common salt effects. The results are listed in Table IV. In two weeks, the EO monomer com- pletely disappeared. The effects of the salts were very remarkable. In comparison with the absence of the salt, the DON yield decreased to about 60 percent and the cyclic tetramer, cyclic pentamer and cyclic hexamer, as well as the linear oligomers were also produced in the presence of an alkali metal salt. The complex formation between a cation and the resulting oligomer was not favorable to the DON production and led to the formation of higher cyclic and linear oligomers. Among the cyclic oligomers, the tetramer and hexamer were produced the most in the systems of lithium, sodium, and potassium salts, respectively. These results are consistent with the complex stability between alkali metal cations and cyclic oligomers. Scheme I shows reaction scheme involved.

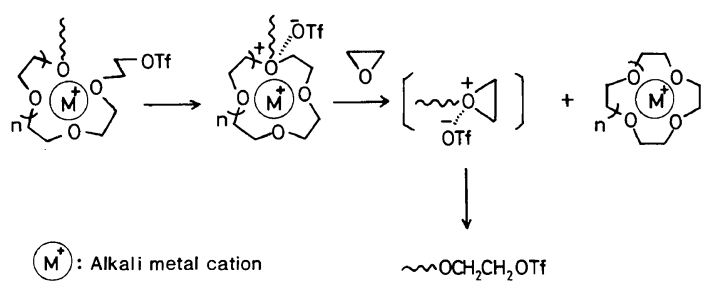

Scheme 1

During the reaction, an appropriate folding of the growing chain is promoted and the subsequent back-biting of DON is retarded by the template effects of the cation. In addition, a linear oligomer complexed with a cation was facilitated in closing a 
ring to form a cyclic oligomer. The complexed cyclic oligomer seemed to be stable and not involved in subsequent reactions. The relative complex stability of the cation determines the size of cyclic oligomer and the amount of its production.

\section{Synthesis of Crown Ethers from Poly (EO)}

Next, we examined the depolymerization of poly(EO) by a cationic catalyst in the presence of an alkali metal salt. Table $\mathrm{V}$ shows the results with $\mathrm{Et}_{3} \mathrm{O}^{+} \cdot \mathrm{BF}_{4}{ }^{-}$or EtOTf in the presence of $\mathrm{LiBF}_{4}$ or LiOTf in $\mathrm{CH}_{2} \mathrm{Cl}_{2}$ at $35^{\circ} \mathrm{C}$. At first, a catalyst $(5$ $\mathrm{mol} \%$ for $\mathrm{EO}$ monomer units of poly(EO)) was added and after one week, the catalyst was added again to this system to complete degradation. In the course of this reaction, cyclic and linear oligomers were formed in addition to DON as the main product. Without the lithium salt, no higher cyclic oligomer was formed. The yield of cyclic oligomers by this method, however, was lower than that of the EO-polymerization. In the case of low molecular weight poly(EO), that is, tetraethylene glycol dimethyl ether, cyclic oligomer yield was also low. The crown ether production from poly(EO) seemed less suitable than that of the EO-polymerization method.

\section{REFERENCES AND NOTES}

1. (a) P. H. Plesch, "The Chemistry of Cationic Polymerization," Pergamon Press, Oxford-London-
New York-Paris, 1963; (b) K. C. Frisch and S. L. Reegen, "Ring Opening Polymerization," Marcel Dekker, New York-London,. 1969; (c) E. J. Goethals, Adv. Polym. Sci., 23, 104 (1977).

2. (a) A. M. Eastham, Fortschr. Hoch. Polym. Forsch., 2, 18 (1960); (b) G. A. Latremouille, G. T. Marral, and A. M. Eastham, J. Am. Chem. Soc., 82, 120 (1960); (c) D. J. Worsforld and A. M. Eastham, ibid., 79, 897 (1957).

3. (a) S. Kobayashi, K. Morikawa, and T. Saegusa, Macromolecules, 8, 952 (1975); (b) S. Kobayashi, K. Morikawa, and T. Saegusa, Polym. J., 11, 405 (1979).

4. (a) J. Dale, G. Borgen, and K. Daasvatn, Acta Chem. Scand., B28, 378 (1974); (b) J. Dale, G. Borgen, and K. Daasvatn, Ger. Pat. Off., 2,401,126 (1974); (c) J. Dale, K. Daasvatn, and T. Gronneberg, Makromol. Chem., 178, 873 (1977); (d) J. Dale and K. Daasvatn, J. Chem. Soc., Chem. Commun., 195 (1976).

5. S. Kobayashi, T. Ashida, and T. Saegusa, Bull. Chem. Soc. Jpn., 47, 1233 (1974).

6. (a) H. Meerwein, E. Batternberg, H. Golad, E. Pfeil, and G. Willfang, J. Prakt. Chem., 154, 83 (1939); (b) H. Meerwein, Org. Syn., 46, 113 (1966).

7. S. Kobayashi, H. Danda, and T. Saegusa, Macromolecules, 7, 415 (1974).

8. H. S. Booth and K. S. Willson, J. Am. Chem. Soc., 57, 2273 (1935).

9. T. Shapiro and H. G. Weiss, J. Am. Chem. Soc., 75, 1753 (1953).

10. S. Kobayashi, K. Morikawa, and T. Saegusa, Macromolecules, 8, 386 (1975).

11. J. Brandrup and M. Goodman, J. Polym. Sci., Polym. Lett. Ed., 2, 123 (1964).

12. R. N. Greene, Tetrahedron Lett., 1793 (1972). 